\title{
Cardiovascular mortality risk in young adults with isolated systolic hypertension: findings from population-based MONICA/KORA cohort study
}

Seryan Atasoy ${ }^{1,2,3}$, Martin Middeke ${ }^{4}$, Hamimatunnisa Johar ${ }^{2,3}$, Annette Peters ${ }^{3}$, Margit Heier ${ }^{3,5}$ and Karl-Heinz Ladwig (iD ${ }^{1,6}{ }^{凶}$

(C) The Author(s) 2021, corrected publication 2023

The clinical significance of isolated systolic hypertension in young adults (ISHY) remains a topic of debate due to evidence ISHY could be a spurious condition resulting from exageratted pulse pressure amplification in "young tall men with elastic arteries". Hence, we aimed to investigate whether ISHY is associated with an increased risk of cardivascular (CVD) mortality in a sample of 5597 young adults (49.8\% men, 50.2\% women) between 25 and 45 years old from the prospective population-based MONICA/ KORA cohort. ISHY was prevalent in $5.2 \%$ of the population, affecting mostly men (73.1\%), and associated with increased smoking, obesity, and hypercholesterolemia in comparison to participants with normal blood pressure (BP). Within a follow-up period of 25.3 years (SD $\pm 5.2 ; 141,768$ person-years), $133(2.4 \%)$ CVD mortality cases were observed. Participants with ISHY had a hazard ratio (HR) of $1.89(1.01-3.53, p<0.05)$ times higher risk of CVD mortality than participants with normal BP, even following adjustment for CVD risk factors. However, adjustment for antihypertensive medication (HR 0.46; 0.26-0.81, $p<0.001$ ) and increasing height (HR 0.96 ; $0.93-0.99, p<0.05)$ revealed independently protective effects against CVD mortality, suggesting that although ISHY is associated with an increased risk of CVD mortality, the protective effects of increasing height or antihypertensive medication should be considered in treatment rationale.

Journal of Human Hypertension (2022) 36:1059-1065; https://doi.org/10.1038/s41371-021-00619-z

\section{INTRODUCTION}

Isolated systolic hypertension (ISH) is currently defined as an elevated systolic blood pressure (SBP) $>140 \mathrm{mmHg}$, combined with a normal diastolic blood pressure $(\mathrm{DBP})<90 \mathrm{mmHg}$ [1]. Consequentially of large artery stiffening and increase in pulse pressure, ISH is the most prevalent subtype of hypertension in the elderly [2]. However, ISH also affects an estimated $2-8 \%$ of the younger indivuals by heterogeneous mechanisms [3, 4]. Nevertheless, whether ISH in the young (ISHY) implies a worse outcome and needs antihypertensive treatment remains debated [5].

The discussion of whether ISHY is clinically significant and needs to be treated stems from two lines of conflicting evidence $[6,7]$. The "pro" argumentation indicates that ISHY is associated with concurrent risk factors such as obesity [8], smoking [3], insulin resistance, and metabolic syndrome [9]. The pathophysiological mechanism between ISHY and worsened health is attributed to hyperkinetic circulation [10, 11] leading to premature aortic stiffening, as supported by previous studies showing a predominantly elevated cardiac output, stroke volume and heart rate in participants with ISHY $[12,13]$. Nevertheless, up to $2 / 3 \mathrm{rd}$ of participants in the aforementioned studies did not present hyperkinetic circulation, leading way for the heterogeneity associated with ISHY.

The "con" side of the argument indicates that ISHY is a spurious condition that should not be treated because it is more prevalent in tall, non-smoking, and physically active men [14-16]. This line of evidence attributes ISHY to exageratted pulse pressure amplification from central to peripheral arteries due to elastic large vessels that are common in tall and young individuals [6]. In line with this, numerous studies have shown that young men with ISHY do not have higher risk factors in comparison to those with normal blood pressure $[6,17,18]$, however, the increase in SBP was confined to the upper limbs and not centrally present in the aorta, nor other arteries [19].

The clinical outcome of ISHY on future cardiovascular disease (CVD) risk also remains unresolved, leading to difficulty with management and prognosis. In line with the pro side of the argument, a recent prospective study has shown that men with ISHY had 28\% higher CVD and 23\% higher CHD (coronary heart disease) mortality risk than men with optimal BP, whereas women with ISHY had 2 times higher CVD and 55\% higher CHD mortality risk over 30 years [17]. However, supporting the con side of the

\footnotetext{
'Department of Psychosomatic Medicine and Psychotherapy, Klinikum Rechts der Isar, Technische Universität München, München, Germany. ${ }^{2}$ Department of Psychosomatic Medicine and Psychotherapy, University of Giessen and Marburg, Giessen, Germany. ${ }^{3}$ Institute of Epidemiology, Helmholtz Zentrum München, German Research Center for Environmental Health, Neuherberg, Germany. ${ }^{4}$ Hypertension Center Munich, a European Society of Hypertension (ESH) Center of Excellence, Munich, Germany. ${ }^{5}$ Kora Study Centre, University Hospital of Augsburg, Augsburg, Germany. ${ }^{6}$ Deutsches Zentrum für Herz-Kreislauf-Forschung (DZHK), Partnersite Munich, Munich, Germany. ${ }^{凶}$ email: karl-heinz.ladwig@tum.de
} 
argument, findings from the HARVEST study indicate that an elevated pulse pressure in participants $<45$ years might actually have a protective role against hypertension, and can largely be attributed to a white-coat effect [18] —an acute stress response to medical environments.

Given the discrepancies in the literature, the present investigation aims to extend the clinical characteristics of ISHY in a population-based cohort, while for the first time, including psychosocial stress conditions. Additionally, to clarify the prognostic value of ISHY and whether it should be treated, the absolute and relative risks of CVD mortality will be examined among the current community-dwelling participants.

\section{METHODS}

The study population was taken from three independent cross-sectional surveys including 5974 participants aged between 25 and 45 years old who participated in the Monitoring of Trends and Determinants in Cardiovascular Disease (MONICA)/Cooperative Health Research in the Region of Augsburg (KORA) cohort study conducted in 1984/1985, 1989/ 1990, and 1994/1995 as part of the multinational World Health Organization (WHO) MONICA project [20]. All procedures contributing to this work comply with the ethical standards of the relevant committees and comply with the Helsinki Declaration of 1975, as revised in 2008 and written consent was obtained from all participants. In the current analysis, missing follow up data $(n=119)$, and missing covariates at baseline $(n=$ 265) led to a pooled sample 5590 participants. A dropout analysis revealed that subjects with missing information were older compared to subjects with available information $(p<0.001)$.

\section{Assessment of hypertension \\ Adhering to WHO MONICA protocol, blood pressure (BP) was measured on the right arm in a sitting position using a Hawksley random-zero sphygmoman- ometer, and measurements were taken half an hour after the clinical interview in 3-min intervals. The average readings of the second and third measurement were considered for the analyzes. An "actual hypertension" [21] measure was used based on the measured blood pressure values, independently of the use of antihypertensive. In line with the ESC/ESH Hypertension Guidelines, isolated- systolic hypertension in the young was defined as brachial $S B P \geq 140 \mathrm{mmHg}$ and DBP $<90 \mathrm{mmHg}$, isolated-diastolic hypertension in the young (IDHY) was defined as $\mathrm{SBP}<140 \mathrm{mmHg}$ and $\mathrm{DBP} \geq 90 \mathrm{mmHg}$, and systolic-diastolic hypertension in the young (SDHY) was defined as $\mathrm{SBP} \geq 140 \mathrm{mmHg}$ and $\mathrm{DBP} \geq 90 \mathrm{mmHg}[1]$.}

\section{Socio-demographic and lifestyle factors}

Low educational level was considered as having less than 12 years of schooling. Physical activity was considered as engaging in physical activity on average of $\geq 1 \mathrm{~h} /$ week throughout the year. Smoking was based on current and regular smoking of $\geq 1$ cigarette/day.

\section{Cardio-metabolic factors}

Total cholesterol and high-density lipoprotein cholesterol were measured as $\mathrm{mg} / \mathrm{dL}$ in serum by enzymatic methods (CHOD-PAP, Boehringer Mannheim, Germany) and dyslipidemia was defined as ratio of total cholesterol to high-density lipoprotein cholesterol $\geq 5.0$. Type 2 diabetes was self reported and confirmed by a physician diagnosis. Trained medical staff measured the body weight $(\mathrm{kg})$ and height $(\mathrm{cm})$ of all participants anthropometrically as part of a standardized medical examination. Calibration of measuring instruments was ensured through weekly or daily inspections using standard weights. Body mass index (BMI) was calculated as weight in kilograms divided by height in meters squared and obesity was defined as having a $\mathrm{BMI} \geq 30 \mathrm{~kg} / \mathrm{m}^{2}$. History of parental hypertension was based on participant's report of either parent with hypertension. Cardiovascular (CVD) conditions were based on a selfreported history of myocardial infarction, heart failure, angina, or stroke.

\section{Psychosocial risk factors}

Depressive symptoms were assessed using the sex-specific top tertiles of the depression and exhaustion subscale of the von Zerssen symptom checklist [22]. Living arrangement was assessed by whether the individual lives alone, irrespectively of relationship status. Sleep complaints were adopted from the Uppsala Sleep Inventory [23] and participants were considered to have sleep complaints if they often had difficulty with initiating and/or maintaining sleep. Job strain was assessed in employed participants by the job content questionnaire [24] and was defined by the quadrant approach where continuous job demands and job control variables were dichotomized by median split [25]. Type A traits were assessed by the Framingham Type A Scale with cut-off points of 0.34 for men and 0.33 for women [26].

Follow-up and mortality endpoints Death certificates were obtained from local health departments and coded for the underlying cause of death by trained personnel using the 9th revision of the International Classification of Diseases (ICD-9). In the present study, fatal CVD events (ICD-9: 390-459) were used as endpoints. During a mean follow-up period of 25.3-years (SD \pm 5.89 years; max: 32 years; 141,768 person years), 133 fatal CVD events (88 in men; 45 in women) were observed. For mortality analyses, event times were calculated as time to death. Subjects without events or with loss to follow-up were censored at the time point of the last follow-up.

\section{Statistical analysis}

The baseline characteristics of the study population between 25 and 45 years with normal BP, ISHY, IDHY, and SDHY were assessed using Pearson's $X^{2}$ for categorical and analysis of variance for continuous variables, and significance of group differences were tested using multivariate logistic regression and Tukey's Method in reference to participants with normal BP.

Absolute CVD mortality rates were calculated using Poisson regression adjusted for baseline survey. The relative risk of CVD mortality in participants with ISHY was given as hazard ratios (HR) using Cox proportional hazards models, where normal BP was the reference group. Four multivariate Cox regression models adjusted for [1] age, sex, survey [2] life-style factors [3] somatic risk factors, and history of CVD and [5] continuously increasing height and antihypertensive medication use were included, where the fully adjusted model included all these covariates.

Proportional hazards could be estimated by fitting models stratified by the risk factor categories and plotting the log-log survival curves for each risk factor, which were assessed for parallelism by visual inspection. As severe deviations from parallelism were not observed for any covariates of CVD events, proportional hazards were assumed. To ensure power of the analyses was at least $80 \%$, a log-rank test was conducted for comparison of survival rates of CVD mortality in the BP categories.

For main analyses, a $p$ value $<0.05$ was statistically significant. All statistical evaluations were performed using SAS 9.4. The analysis and the description in this manuscript follow the STROBE guidelines for cohort studies.

\section{RESULTS}

The present data were derived from a total of 5597 participants (49.8\% men, $50.2 \%$ women) at baseline with a mean age of 35.2 years (SD \pm 6.1 ), of whom $5.2 \%$ ( $73.1 \%$ men, $26.9 \%$ women) had ISHY, 6.7\% (71\% men, 29\% women) had IDHY and 7.6\% $(73.1 \%$ men, $26.9 \%$ women) had SDHY. At baseline, men with ISHY were taller than participants with IDHY and SDHY, yet there was no significant difference of height between participants with ISHY and normal BP. However, women with ISHY were more likely to have a shorter height than all remaining groups.

As shown in Table 1, ISHY had increased concurrent risk factors in comparison to participants with normal BP, whereby they were more likely to be male, smoke regularly, have obesity, dyslipidemia, and high pulse pressure. On the other hand, participants with ISHY and normal BP had no significant difference in age and physical activity, whereas participants with ISHY had even lower levels of job strain and type A traits than participants with normal BP.

In comparison to participants with normal BP, IDHY and SDHY posed a more amplified risk factor profile than ISHY, whereby they were more likely to be older, physically inactive, have obesity, dyslipidemia, history of CVD conditions, type 2 diabetes. An exception to this trend was with smoking, which remained substantially higher in participants with ISHY.

\section{Absolute CVD mortality rates}

During a mean follow-up period of 25.3 years ( $S D \pm 5.89$ ), 133 (2.4\%) fatal CVD events were observed, including 88 events 
Table 1. Baseline characteristics of CVD risk factors in the MONICA/KORA Cohort, according to BP groups $(N=5597)$.

\begin{tabular}{|c|c|c|c|c|c|}
\hline \multirow[t]{2}{*}{ Baseline characteristics } & \multicolumn{5}{|c|}{ Prevalence, $n$ (\%) } \\
\hline & Total & Normal BP & ISHY & IDHY & SDHY \\
\hline Total & $5597(100.0)$ & $4504(80.4)$ & $290(5.2)$ & $376(6.7)$ & $427(7.6)$ \\
\hline Women & $2807 \quad(50.2)$ & $2505(55.6)$ & $78(26.9)^{* * *}$ & $109(29.0)^{* * *}$ & $115(26.9)^{* * *}$ \\
\hline Mean age (years) $( \pm S D)$ & $35.2(6.1)$ & $34.7(6.1)$ & $35.5(6.8)$ & $37.4(5.4)^{* * *}$ & $38.6(5.3)^{* * *}$ \\
\hline Education ( $\leq 12$ yrs) & $3647(65.2)$ & $2907(64.5)$ & $192(66.2)$ & $246(65.4)$ & $302(70.7)$ \\
\hline Physically inactive & $2791(49.9)$ & $2208(49.0)$ & $146(50.3)$ & $206(54.8)^{*}$ & $231(54.1)^{*}$ \\
\hline Systolic BP ( \pm SD) & $123.8(14.5)$ & $119.0(10.4)$ & $146.0(6.4)^{* * *}$ & $132.4(5.3)^{* * *}$ & $151.9(11.8)^{* * *}$ \\
\hline Diastolic BP $( \pm S D)$ & $78.0(11.1)$ & $74.5(8.4)$ & $81.6(7.3)^{* * *}$ & $93.2(3.2)^{* * *}$ & $98.9(7.5)^{* * *}$ \\
\hline High pulse pressure & $481(8.6)$ & $183(4.1)$ & $158(55.0)^{* * *}$ & 0 & $65(15.2)^{* * *}$ \\
\hline Height $(\mathrm{cm})( \pm \mathrm{SD})$ Men & $176.7(6.6)$ & $176.9(6.5)$ & $177.2(6.9)$ & $175.4(6.4)^{*}$ & $175.6(6.5)^{*}$ \\
\hline Obesity $^{\mathrm{a}}$ & $636(11.4)$ & $384(8.5)$ & $43(14.8)^{* * *}$ & $89(23.7)^{* * *}$ & $120(28.1)^{* * *}$ \\
\hline Dyslipidemia $^{\mathrm{b}}$ & $1329(23.7)$ & $889(19.7)$ & $94(32.4)^{* * *}$ & $150(39.9)^{* * *}$ & $196(45.9)^{* * *}$ \\
\hline Type 2 diabetes & $29(0.52)$ & $17(0.38)$ & $3(1.03)$ & $3(0.80)$ & $6(1.41)^{* *}$ \\
\hline Parental history & $2249(40.2)$ & 1749 (38.9) & $128(44.1)$ & $164(43.6)$ & $208(48.7)^{* * *}$ \\
\hline Treatment $^{c}$ & $158(2.8)$ & $70(1.6)$ & $17(5.9)^{* * *}$ & $17(4.5)^{* * *}$ & $54(12.7)^{* * *}$ \\
\hline History of CVD ${ }^{d}$ & $97(1.73)$ & $73(1.6)$ & $3(1.03)$ & $11(2.9)$ & $10(2.3)$ \\
\hline Depressive symptoms & $993(19.2)$ & $800(19.2)$ & $44(16.9)$ & $75(21.7)$ & 74 (18.9) \\
\hline Job strain & $1035(26.3)$ & $836(27.0)$ & $40(17.6)^{* *}$ & $64(22.1)^{*}$ & $95(29.2)$ \\
\hline Type A traits & $2422(45.6)$ & $1957(45.7)$ & $102(37.8)^{*}$ & $187(52.1)^{*}$ & $176(43.9)$ \\
\hline Living alone & $1218(21.8)$ & $997(22.1)$ & $64(22.1)$ & $76(20.2)$ & $81(19.0)$ \\
\hline
\end{tabular}

in men and 45 events in women (Fig. 1). In general, participants with ISHY had a significantly higher absolute CVD mortality rate than participants with normal BP (1.5 vs. 0.6 cases $/ 1000$ person-years (py), $p=0.001)$. Likewise, participants with IDHY ( 1.3 cases $/ 1000$ py, $p=0.004)$ and SDHY (2.6 cases/1000 py, $p<$ $0.0001)$ experienced higher CVD mortality in comparison to participants with normal BP. However, as shown in Fig. 2, the mortality rate revealed significant sex differences, whereby men with ISHY were nearly two times more likely to experience CVD mortality than women with ISHY $(p>0.0001)$. However, large sex differences were not observed in participants with IDHY or SDHY.

\section{Relative risk of CVD mortality}

Within a mean of 25.3 years of follow-up, participants with ISHY had a $1.89(95 \% \mathrm{Cl} 1.01-3.53, p<0.05)$ times higher relative risk of CVD mortality in comparison to participants with normal BP (Table 2). Participants with SHDY had an even higher risk of CVD mortality by a hazard ratio of $2.36(95 \% \mathrm{Cl} 1.50-3.72, p<0.001)$, but participants with IDHY did not experience a significantly higher risk of CVD mortality than participants with normal BP (HR 1.44; $95 \% \mathrm{Cl} 0.80-2.59, p=0.28)$. Altogether, ISHY was associated with a lower risk of CVD mortality than participants with SDHY (HR $0.76 ; 0.39-1.49, p=0.43)$, but a higher risk than participants with IDHY (HR 1.32; 95\% Cl 0.61-2.88, $p=0.47$ ), although these differences did not reach statistical significance.
Concurrent risk factors, including being male (HR 2.98; $\mathrm{Cl}$ 1.50-5.86, $p=0.002$ ), smoking (HR 1.83; 95\% Cl 1.28-2.60, $p<$ 0.001 ) dyslipidemia (HR 1.85; $95 \% \mathrm{Cl} 1.12-3.07, p=0.02$ ), type 2 diabetes (HR 4.72; $\mathrm{Cl} 1.88-11.87, p<0.001$ ) and suffering from a history of CVD conditions (HR 1.78; $95 \% \mathrm{Cl} 1.00-3.18, p<0.05$ ) were significant in increasing the risk of CVD mortality in participants with hypertension. On the other hand, protective effects of increasing height and antihypertensive treatment were observed, whereby every $1 \mathrm{~cm}$ increase in height was associated with a $4 \%$ (HR 0.96; 95\% Cl 0.93-0.99, $p=0.02)$ lowered risk of CVD mortality, and/or the use of antihypertensive treatment was associated with a 54\% (HR 0.46; 95\% Cl 0.26-0.81, $p<0.001)$ lowered risk of CVD mortality.

Furthermore, sex stratified results in the adjusted models revealed that men with ISHY had a 1.99 (95\% Cl 0.99-3.99, $p=$ 0.05 ) times higher risk of CVD mortality than men with normal BP, whereas women with ISHY did not experience a significantly higher risk of mortality than women with normal BP (HR 1.29; $95 \%$ Cl $0.30-5.55, p=0.73$ ).

\section{Sensitivity analysis}

Following the exclusion of participants with CVD conditions and/ or antihypertensive treatment $(n=238)$, ISHY remained associated with a $1.94(95 \% \mathrm{Cl} 0.99-3.80, p=0.05)$ increased risk of CVD mortality, albeit with a borderline statistical significance. Additionally, participants with SDHY experienced a significantly higher 

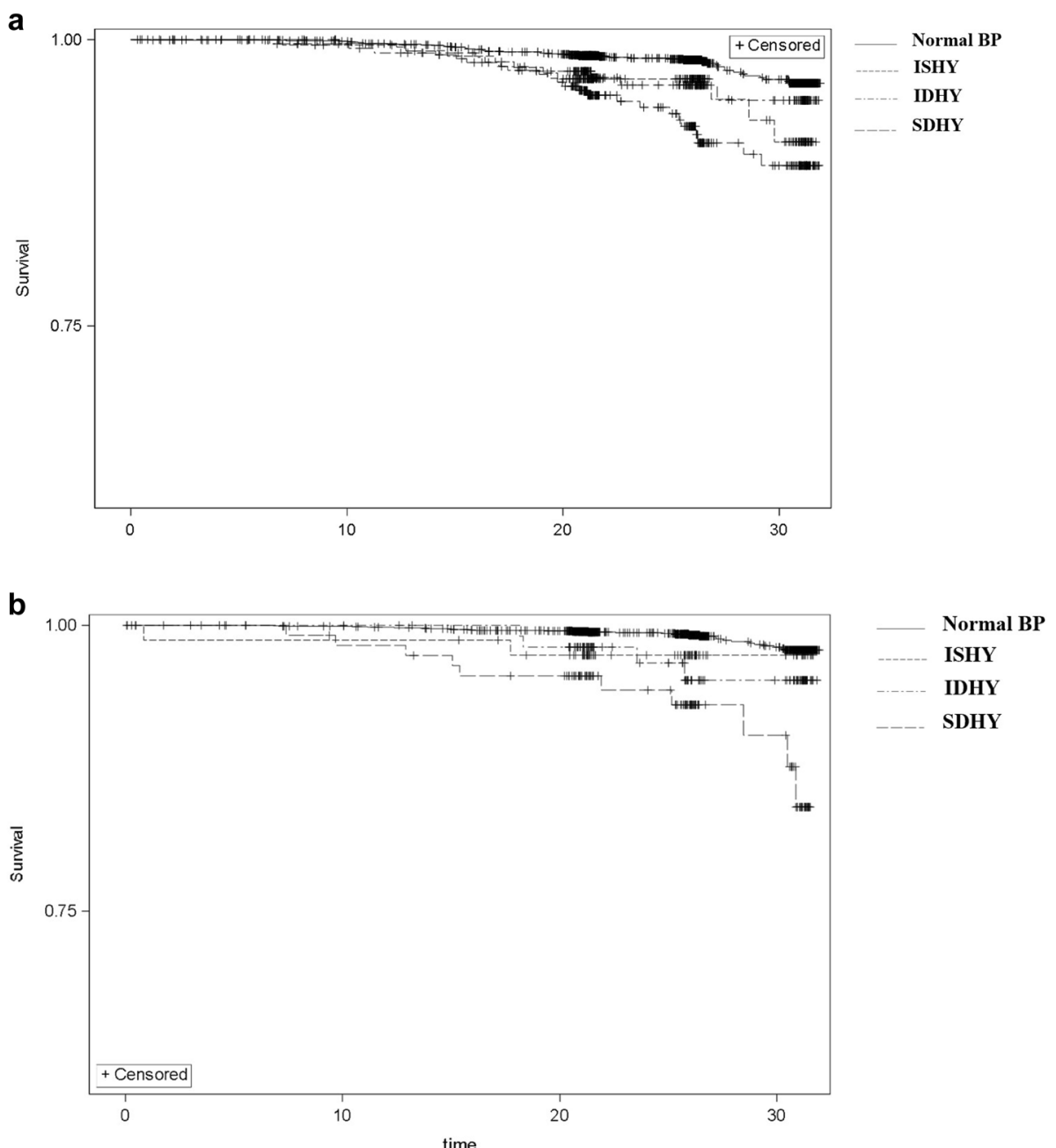

Fig. 1 a Kaplan-Meier survival curve for CVD mortality in men according to blood pressure groups in the MONICA/KORA Cohort ( $n=2790$ ). *Analyses based on 88 fatal CVD events. BP blood prssure; CVD cardiovascular disease; ISHY isolated systolic hypertension in the young; IDHY isolated diastolic hypertension in the young; SDHY systolic-diastolic hypertension in the young. b Kaplan-Meier survival curve for CVD mortality in women according according to blood pressure groups in the MONICA/KORA Cohort $(n=2807)$. ${ }^{*}$ Analyses based on 45 fatal CVD events. BP blood pressure; CVD cardiovascular disease; ISHY isolated systolic hypertension in the young; isolated diastolic hypertension in the young; $S D H Y$ systolic-diastolic hypertension in the young.

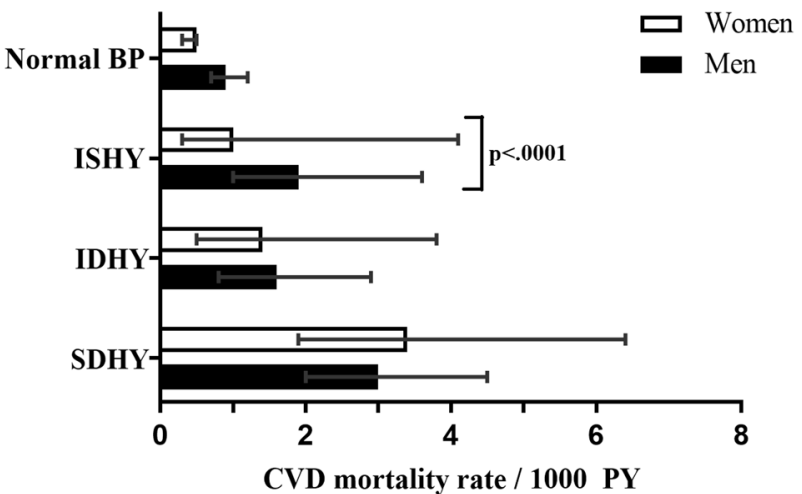

Fig. 2 Sex-stratified absolute CVD mortality rates of the MONICA/ KORA Cohort, according to blood pressure groups $(N=5597)$. *Analyses based on 133 fatal CVD events **Error bars represent $95 \%$ Cl. BP blood pressure; CVD cardiovascular disease; ISHY isolated systolic hypertension in the young; IDHY isolated diastolic hypertension in the young; SDHY systolic-diastolic hypertension in the young. risk of CVD mortality in comparison to participants with normal BP (HR 2.35; 95\% Cl 1.42-3.90, $p<0.001$ ), whereas participants with IDHY did not reach a significance in their risk of CVD mortality (HR $1.41 ; 95 \% \mathrm{Cl} 0.73-2.71, p=0.30)$.

\section{DISCUSSION}

Due to the ongoing dispute about the clinical significance of ISHY [5], the present study focused on the characteristics and prospective risk of CVD mortality associated with ISHY in a population-based cohort. The findings herein confirmed that ISHY is a clinically heterogenous condition [4], whereby participants with ISHY were more likely to be obese, smoke, have increased pulse pressure and somatic risk factors in comparison to participants with normal BP. They were nevertheless of similar age, had comparable physical activity levels, and had an even lower prevalence of psychosocial impairment. Despite the heterogeneity of the condition, participants-with ISHY- largely comprised of men-suffered from $89 \%$ higher risk of CVD mortality in comparison to participants with normal BP participants during the follow-up period. 
Table 2. Hazard ratios of CVD mortality in participants with ISHY $(n=290)$, IDHY $(n=376)$, and SDHY $(n=427)$ in comparison to normal BP participants $(n=4504)$ from the MONICA/KORA Cohort $(\mathrm{HR}, 95 \% \mathrm{Cl}, p)$.

\begin{tabular}{|c|c|c|c|c|}
\hline Variable & $\begin{array}{l}\text { Model } 1 \\
H R(95 \% C l)\end{array}$ & $\begin{array}{l}\text { Model } 2 \\
\text { HR }(95 \% \text { CI) }\end{array}$ & $\begin{array}{l}\text { Model } 3 \\
\text { HR }(95 \% \mathrm{Cl})\end{array}$ & $\begin{array}{l}\text { Model } 4 \\
H R(95 \% \mathrm{CI})\end{array}$ \\
\hline IDHY & $1.67(0.93-2.97)$ & $1.69(0.94-3.02)$ & $1.52(0.85-2.72)$ & $1.44(0.80-2.59)$ \\
\hline Men & $1.85(1.27-2.69)^{* *}$ & $1.73(1.18-2.52)^{* *}$ & $1.38(0.92-2.08)$ & $2.02(1.19-3.44)^{* *}$ \\
\hline Age (years) & $1.10(1.06-1.13)^{* * *}$ & $1.10(1.07-1.14)^{* * *}$ & $1.09(1.06-1.13)^{* * *}$ & $1.08(1.05-1.12)^{* * *}$ \\
\hline Physical inactivity & - & $1.50(1.05-2.15)^{*}$ & $1.39(0.97-2.00)$ & $1.34(0.93-1.93)$ \\
\hline Obesity & - & - & $1.43(0.94-2.20)$ & $1.36(0.89-2.09)$ \\
\hline Dyslipidemia $^{\text {b }}$ & - & - & $1.82(1.23-2.67)^{* *}$ & $1.73(1.18-2.55)^{* *}$ \\
\hline History of CVD ${ }^{c}$ & - & - & $2.40(1.11-5.20)^{*}$ & $2.18(1.01-4.75)^{*}$ \\
\hline
\end{tabular}

Analyses based on 133 fatal CVD events.

$B P$ blood pressure, $C V D$ cardiovascular disease, ISHY (isolated systolic hypertension in young adults

${ }^{*} p<0.05,{ }^{* *} p<0.01,{ }^{* * *} p<0.001$.

${ }^{a} \leq 12$ years of education.

${ }^{\mathrm{b}}$ Ratio of total cholesterol to high-density lipoprotein cholesterol $\geq 5.0$.

'History of myocardial infarction, heart failure, angina, or stroke.

dUse of antihypertensive medication.

Although previous evidence suggests that ISHY has different underlying mechanisms than ISH in the elderly [5], the baseline characteristics reported herein revealed that risk factors associated with ISHY are generally comparable to older participants, albeit less prevalent. The results herein strengthened previous findings that risk factors including smoking, low education, and high BMI are associated with ISHY [3, 27, 28]. However, the current results concurrently supported previous findings that ISHY is more common in taller men who are more likely to be physically active in comparison to other young hypertension groups [14, 15], but in contrast to this line of evidence, ISHY was associated with smoking more than any other BP group. Hence, the detrimental effect of smoking on arterial stiffness and acceleration of age-related decline in blood pressure amplification in young individuals is thought to be one of the main pathways to ISHY in the current investigation $[29,30]$.

Despite previously reported associations between ISHY and white coat hypertension [18] - which is appraised as an acute stress response condition-the current study revealed that ISHY was in fact not associated with sustained stress conditions. In contrast, ISHY experienced the lowest job strain and type A behavior pattern in comparison to all remaining BP groups. However, the current findings may be discerned in light of findings linking higher systolic BP to lower psychological distress [31]. Additionally, the lower psychosocial stress conditions in ISHY could be driven by the substantially high smoking rate in these individuals, previously put forth as Nesbitt's paradox. Within this concept, nicotine acts as a physiological stimulant which is actually perceived as tranquilizing to the individual smoking [32] all the while contributing to increased SBP [29].

During a mean 25-years follow up period, ISHY suffered from 1.5 cases/1000 person-years of absolute CVD mortality rates, corresponding to a 1.89 times higher adjusted relative CVD mortality risk in comparison to participants with normal BP. In line with a previous study by Yano et al. [17], "ISH risks were higher than in those with high-normal BP or isolated diastolic hypertension and less than those associated with systolic diastolic hypertension". However, the overall risk associated with ISHY reported herein particularly in men - was higher than the ISHY risk reported by Yano et al. [17], whereby ISHY increased incidence of CVD mortality by HR of 1.23 in men and 1.55 in women. However, differences between the two populations, including the larger sample size, more women with ISHY and younger age range of participants between 18 and 49 years may partially explain these discrepancies. Furthermore, it is possible that the results by Yano et al. [17], may have been underestimated as their BP measurement was based on a single casual supine measurement, a position which can result to a lower systolic and higher diastolic BP measurement in comparison to the sitting position [33].

The prospective findings herein further supported attributes of both the "pro" and "con" sides of the ISHY debate $[6,7]$ protective effects of increasing height, as well as anti-hypertensive treatment against the risk of CVD mortality, was evident. In line with the aforementioned 'tall men with elastic arteries' argument [13-15], each 1-cm increase in height independently decreased the CVD mortality risk by $4 \%$, confirming findings by a recent Mendelian Randomization study showing that genetically predicted height is causally associated with higher systolic BP, as was the case in men with ISHY in the current study, as well as lower arterial stiffness [34]. However, the overall effect of ISHY on the risk of CVD mortality remained substantial even following adjustments for protective factors, indicating that ISHY is an independent and significant predictor of CVD mortality.

The main limitation of the current study is that direct cause and effect relationships cannot be discerned due to lack of ambulatory or central BP measures, white-coat effect estimation with any outof-office measurement and arterial stiffness parameters. Furthermore, the absence of information about time-varying phenomena during the follow-up period, including the incidence of SDHY in ISDHY and IDHY subjects, changes in BP and/or start of antihypertensive medication or other cardio-protective drug agents is a limitation that is innate in such study designs. 
Additionally, the mortality cases during the follow-up period were relatively low, however, this study is representative of the realworld situation in which young adults in the general population have increasing lifespans. Similarly, as $73 \%$ of baseline ISHY cases were men, the current ISHY-CVD mortality link is largely representative of men rather then women. On the other hand, the strengths of the current study include the reliable measurement of BP, heterogeneity of many participants randomly drawn from the population, as well as the considerable data on psychosocial risk factors.

In conclusion, the difference between baseline SBP and DBP in ISHY is associated with a variety of heterogeneous demographic, lifestyle, anthropometric, somatic, and psychosocial characteristics. Nevertheless, ISHY independently heightens the future risk of CVD mortality - particularly in men. However, as height emerges as an additional factor with a protective role against the risk of CVD mortality, central BP measures should nowadays be monitored for the treatment rationale of tall men who present ISHY.

\section{Summary Table}

What is known about the topic

- Previous studies have shown that isolated systolic hypertension in young adults is a clinically heterogenous conditionalthough isolated systolic hypertension in young adults has been associated with concurrent risk factors including smoking and obesity, it has also been associated with nonclinical factors including 'elastic arteries' present in tall and physically active men.

- However, whether isolated systolic hypertension in young adults increases the future risk of cardiovascular mortality remains unresolved-particularly among tall individuals who may have increased systolic blood pressure in the peripheries, yet not centrally.

\section{What this study adds}

- The study shows that young adults with isolated systolic hypertension have substantially higher concurrent risk factors than normal BP young adults, yet they are also significantly more likely to be taller.

- Young adults with isolated systolic hypertension have a substantially higher risk of cardiovascular mortality in comparison to their normal BP counterparts.

- However, protective effects of antihypertensive medication and increasing height in young adults with systolic hypertension should be considered in treatment rationale.

\section{CODE AVAILABILITY}

The current data and code can be requested from the MONICA/KORA-Myocardial Infarction Registry in Augsburg, Germany.

\section{REFERENCES}

1. Williams B, Mancia G, Spiering W, Agabiti Rosei E, Azizi M, Burnier M, et al. ESC/ ESH Guidelines for the management of arterial hypertension. Eur Heart J. 2018;39:3021-104.

2. Kibria GMA. Prevalence and Trends of Isolated Systolic Hypertension among Untreated Older People in the US according to the 2017 ACC/AHA Guideline, 2001-16. J Hum Hypertens. 2021;35:101-3.

3. Grebla RC, Rodriguez CJ, Borrell LN, Pickering TG. Prevalence and determinants of isolated systolic hypertension among young adults: the 1999-2004 US National Health And Nutrition Examination Survey. J Hypertens. 2010;28:15-23.
4. Eeftinck Schattenkerk DW, van Gorp J, Vogt L, Peters RJ, van den Born BH. Isolated systolic hypertension of the young and its association with central blood pressure in a large multi-ethnic population. The HELIUS study. Eur J Prev Cardiol. 2018;25:1351-9.

5. Palatini P, Rosei EA, Avolio A, Bilo G, Casiglia E, Ghiadoni L, et al. Isolated systolic hypertension in the young: a position paper endorsed by the European Society of Hypertension. J Hypertens. 2018;36:1222-36.

6. Lurbe E, Redon J. Isolated systolic hypertension in young people is not spurious and should be treated: con side of the argument. Hypertension. 2016;68:276-80.

7. McEniery CM, Franklin SS, Cockcroft JR, Wilkinson IB. Isolated systolic hypertension in young people is not spurious and should be treated: pro side of the argument. Hypertension. 2016;68:269-75.

8. Lurbe E, Torro Ml, Alvarez-Pitti J, Redon P, Redon J. Central blood pressure and pulse wave amplification across the spectrum of peripheral blood pressure in overweight and obese youth. J Hypertens. 2016;34:1389-95.

9. Strazzullo P, Barba G, Cappuccio FP, Siani A, Trevisan M, Farinaro E, et al. Altered renal sodium handling in men with abdominal adiposity: a link to hypertension. J Hypertens. 2001;19:2157-64.

10. Julius S, Krause L, Schork NJ, Mejia AD, Jones KA, van de Ven C, et al. Hyperkinetic borderline hypertension in Tecumseh, Michigan. J Hypertens. 1991;9:77-84.

11. Middlemiss JE, Miles KL, McDonnell BJ, Yasmin, Maki-Petaja KM, Cockcroft JR, et al. Mechanisms underlying elevated SBP differ with adiposity in young adults: the Enigma study. J Hypertens. 2016;34:290-7.

12. McEniery CM, Yasmin, Wallace S, Maki-Petaja K, McDonnell B, Sharman JE, et al. Increased stroke volume and aortic stiffness contribute to isolated systolic hypertension in young adults. Hypertension. 2005;46:221-6.

13. Julius $S$, Jones K, Schork N, Johnson E, Krause L, Nazzaro P, et al. Independence of pressure reactivity from pressure levels in Tecumseh, Michigan. Hypertension. 1991;17:II112-21. 4 Suppl

14. O'Rourke MF, Vlachopoulos C, Graham RM. Spurious systolic hypertension in youth. Vasc Med. 2000;5:141-5

15. Mahmud A, Feely J. Spurious systolic hypertension of youth: fit young men with elastic arteries. Am J Hypertens. 2003;16:229-32.

16. Hulsen HT, Nijdam M-E, Bos W-J, Uiterwaal CS, Oren A, Grobbee DE, et al. Spurious systolic hypertension in young adults; prevalence of high brachial systolic blood pressure and low central pressure and its determinants. J Hypertens. 2006;24:1027-32.

17. Yano Y, Stamler J, Garside DB, Daviglus ML, Franklin SS, Carnethon MR, et al. Isolated systolic hypertension in young and middle-aged adults and 31-year risk for cardiovascular mortality: the Chicago Heart Association Detection Project in Industry study. J Am Coll Cardiol. 2015;65:327-35.

18. Saladini F, Fania C, Mos L, Mazzer A, Casiglia E, Palatini P. Office pulse pressure is a predictor of favorable outcome in young-to middle-aged subjects with stage 1 hypertension. Hypertension. 2017;70:537-42.

19. O'Rourke MF, Adji A. Guidelines on guidelines: focus on isolated systolic hypertension in youth. J Hypertens. 2013;31:649-54.

20. Lowel H, Doring A, Schneider A, Heier M, Thorand B, Meisinger C, et al. The MONICA Augsburg surveys-basis for prospective cohort studies. Gesundheitswesen. 2005;67:S13-8. Suppl 1.

21. Atasoy S, Johar $\mathrm{H}$, Peters A, Ladwig K-H. Association of hypertension cut-off values with 10-year cardiovascular mortality and clinical consequences: a realworld perspective from the prospective MONICA/KORA study. Eur Heart J. 2018: ehy694-ehy.

22. Ladwig KH, Marten-Mittag B, Baumert J, Lowel H, Doring A, Investigators K. Casefinding for depressive and exhausted mood in the general population: reliability and validity of a symptom-driven diagnostic scale. Results from the prospective MONICA/KORA Augsburg Study. Ann Epidemiol. 2004;14:332-8.

23. Mallon L, Broman JE, Hetta J. Sleep complaints predict coronary artery disease mortality in males: a 12-year follow-up study of a middle-aged Swedish population. J Intern Med. 2002;251:207-16.

24. Theorell T, Tsutsumi A, Hallquist J, Reuterwall C, Hogstedt C, Fredlund P, et al. Decision latitude, job strain, and myocardial infarction: a study of working men in Stockholm. The SHEEP Study Group. Stockholm Heart Epidemiology Program. Am J Public Health. 1998;88:382-8.

25. Emeny RT, Zierer A, Lacruz ME, Baumert J, Herder C, Gornitzka G, et al. Job strainassociated inflammatory burden and long-term risk of coronary events: findings from the MONICA/KORA Augsburg case-cohort study. Psychosom Med. 2013;75:317-25.

26. Haynes SG, Levine S, Scotch N, Feinleib M, Kannel WB. The relationship of psychosocial factors to coronary heart disease in the Framingham study. I. Methods and risk factors. Am J Epidemiol. 1978;107:362-83.

27. Asgari S, Khalili D, Mehrabi Y, Kazempour-Ardebili S, Azizi F, Hadaegh F. Incidence and risk factors of isolated systolic and diastolic hypertension: a 10 year follow-up of the Tehran Lipids and Glucose Study. Blood Press. 2016;25:177-83. 
28. Strazzullo P, Barbato A, Galletti F, Barba G, Siani A, lacone R, et al. Abnormalities of renal sodium handling in the metabolic syndrome. Results of the Olivetti Heart Study. J Hypertens. 2006;24:1633-9.

29. Mahmud A, Feely J. Effect of smoking on arterial stiffness and pulse pressure amplification. Hypertension. 2003;41:183-7.

30. Saladini F, Benetti E, Fania C, Mos L, Casiglia E, Palatini P. Effects of smoking on central blood pressure and pressure amplification in hypertension of the young. Vasc Med. 2016;21:422-8.

31. Hamer M, Batty GD, Stamatakis E, Kivimaki M. Hypertension awareness and psychological distress. Hypertension. 2010;56:547-50.

32. Dunn WL. Smoking behavior: motives and incentives. VH Winston \& Sons; 1973.

33. Pickering TG, Hall JE, Appel LJ, Falkner BE, Graves JW, Hill MN, et al. Recommendations for blood pressure measurement in humans: an AHA scientific statement from the Council on High Blood Pressure Research Professional and Public Education Subcommittee. J Clin Hypertens. 2005;7:102-9.

34. Tan LE, Llano A, Aman A, Dominiczak AF, Padmanabhan S. A18709 Mendelian Randomization study of causal relationship of height on blood pressure and arterial stiffness. J Hypertens. 2018;36:e91-e2.

\section{AUTHOR CONTRIBUTIONS}

$\mathrm{SA}, \mathrm{KHL}$, and MM were involved in the conception and design of the manuscript. SA and $\mathrm{HJ}$ conducted statistical analyses and SA drafted the manuscript. $\mathrm{MH}$ and $\mathrm{AP}$ were involved in data acquisition and quality assessment. KHL supervised the project. All authors reviewed the manuscript.

\section{FUNDING}

The KORA research platform and the KORA Augsburg studies are financed by the Helmholtz Zentrum München, German Research Center for Environmental Health, which is funded by the German Federal Ministry of Education and Research (BMBF) and by the State of Bavaria. This work was additionally supported by the Munich Heart Alliance. Open Access funding enabled and organized by Projekt DEAL.

\section{COMPETING INTERESTS}

The authors declare no competing interests.

\section{ADDITIONAL INFORMATION}

Correspondence and requests for materials should be addressed to Karl-Heinz Ladwig.

Reprints and permission information is available at http://www.nature.com/ reprints

Publisher's note Springer Nature remains neutral with regard to jurisdictional claims in published maps and institutional affiliations.

Attribution 4.0 International License, which permits use, sharing, adaptation, distribution and reproduction in any medium or format, as long as you give appropriate credit to the original author(s) and the source, provide a link to the Creative Commons license, and indicate if changes were made. The images or other third party material in this article are included in the article's Creative Commons license, unless indicated otherwise in a credit line to the material. If material is not included in the article's Creative Commons license and your intended use is not permitted by statutory regulation or exceeds the permitted use, you will need to obtain permission directly from the copyright holder. To view a copy of this license, visit http://creativecommons. org/licenses/by/4.0/.

(c) The Author(s) 2021, corrected publication 2023 